\title{
Memórias de gestores de escolas rurais durante a Ditadura Civil-Militar brasileira (1964-1985)
}

\author{
Memories of rural school managers during the \\ Brazilian Civil-Military Dictatorship (1964-1985)
}

Recuerdos de gerentes de escuelas rurales durante el Dictadura Civil-Militar brasileña (1964-1985)

\author{
Darciel Pasinato \\ Universidade do Vale do Rio dos Sinos (Brasil) \\ https://orcid.org/0000-0003-4167-2025 \\ http://lattes.cnpq.br/0365700249114929 \\ darcielpasinato1986@gmail.com
}

\section{Resumo}

O objetivo do artigo é investigar as memórias de gestores das Escolas Aníbal Magni e Frei Anselmo, localizadas no interior do município de Selbach, no norte do Rio Grande do Sul, no período que compreende a Ditadura Civil-Militar brasileira entre 1964 e 1985. Estudando as vinculações estabelecidas entre as instituições e os procedimentos pelos quais as representações da institucionalização destas escolas foram estabelecidas, é que se pode perceber e entender atitudes e condutas históricas produzidas coletivamente. Com foco no eixo das instituições escolares, tem a Memória como pressuposto teórico e utiliza a metodologia da História Oral. Por fim, no que diz respeito ao perfil dos gestores escolares, prevalece o foco no pedagógico, dado que os gestores eram responsáveis por conduzir questões de ensino e aprendizagem, ao lado dos docentes. Consideremos que os gestores colaboraram com a educação das comunidades onde atuaram, tornando-se evidente nas narrativas de memória, no reconhecimento que recebem dos seus ex-alunos.

Palavras-chave: Memórias de gestores. Ditadura Civil-Militar brasileira. História Oral. 


\begin{abstract}
The objective of the article is to investigate the memories of managers of the Aníbal Magni and Frei Anselmo Schools, located in the interior of the municipality of Selbach, in the north of Rio Grande do Sul, in the period between the Brazilian Civil-Military Dictatorship between 1964 and 1985 Studying the links established between the institutions and the procedures by which the representations of the institutionalization of these schools were established, it is possible to perceive and understand historical attitudes and conduct produced collectively. Focusing on the axis of school institutions, it has Memory as its theoretical assumption and uses the methodology of Oral History. Finally, with regard to the profile of school managers, the focus on pedagogy prevails, given that managers were responsible for conducting teaching and learning issues, alongside teachers. Consider that the managers collaborated with the education of the communities where they worked, this is evident in the narratives of memory, in the recognition they receive from their former students.
\end{abstract}

Keywords: Manager's memories. Brazilian Civil-Military Dictatorship. Oral History.

\title{
Resumen
}

El objetivo del artículo es investigar los recuerdos de los administradores de las Escuelas Aníbal Magni y Frei Anselmo, ubicadas en el interior del municipio de Selbach, en el norte de Rio Grande do Sul, en el período comprendido entre la Dictadura Civil-Militar brasileña entre 1964 y 1985. Al estudiar los vínculos establecidos entre las instituciones y los procedimientos por los cuales se establecieron las representaciones de la institucionalización de estas escuelas, es posible percibir y comprender las actitudes y conductas históricas producidas colectivamente. Centrándose en el eje de las instituciones escolares, tiene la memoria como suposición teórica y utiliza la metodología de la historia oral. Finalmente, con respecto al perfil de los gerentes de las escuelas, prevalece el enfoque en la pedagogía, dado que los gerentes eran responsables de conducir los problemas de enseñanza y aprendizaje, junto con los maestros. Considere que los gerentes colaboraron con la educación de las comunidades donde trabajaban, esto es evidente en las narrativas de la memoria, en el reconocimiento que reciben de sus antiguos alumnos.

Palabras clave: Recuerdos del gerente. Dictadura Civil-Militar brasileña. Historia oral. 


\section{Introdução}

Este artigo é fruto de uma pesquisa de Pós-doutorado, desenvolvida junto ao Programa de Pós-Graduação em Educação da Universidade do Vale do Rio dos Sinos (UNISINOS) sob a supervisão da Professora Dra. Flávia Obino Corrêa Werle, financiado pelo Programa Nacional de Pós-Doutorado (PNPD/CAPES). Nesta perspectiva, foi realizado um estudo a partir de uma experiência sobre memórias de gestores de duas pequenas escolas rurais de um município localizado no norte do Rio Grande do Sul, para realização de pesquisa acadêmica no campo da História da Educação, com foco no eixo das instituições escolares, que tem a Memória como pressuposto teórico e utiliza a metodologia da História Oral.

A memória tem se tornado uma preciosa fonte de pesquisa, e as produções neste ramo vêm aumentando significativamente, uma vez que ela traz uma parte do passado que não foi registrada por intermédio de fotos ou outros meios de guarda, visto que esses momentos foram apenas vividos. Desta maneira, não deve mais ser tratada como um processo limitado de lembrar fatos já transcorridos, mas como uma coluna do fazer histórico, conduzindo referências de diferentes grupos sociais. Por essa razão, vem se descobrindo outra perspectiva, uma nova forma de olhar para as vivências e lembranças do construto histórico.

Estudando as vinculações estabelecidas entre as instituições e os procedimentos pelos quais as representações da institucionalização destas escolas foram determinadas, é que se pode perceber e entender atitudes e condutas históricas produzidas coletivamente. Examinar a dinâmica destas relações pressupõe assimilar como os membros de determinados grupos se envolveram diante dos estímulos e pressões externas.

A pesquisa tem o meio rural como cenário, cujas práticas e representações locais geraram os elementos culturais que criaram o modo como foram sendo instituídas as escolas nas comunidades de Arroio Grande (Escola Aníbal Magni) e Linha Floresta (Escola Frei Anselmo). O artigo tem por objetivo investigar as memórias de gestores das Escolas Aníbal Magni e Frei Anselmo, localizadas no interior do município de Selbach, no norte do Rio Grande do Sul, no período que compreende a Ditadura Civil-Militar brasileira entre 1964 e 1985. O artigo, além da introdução e das considerações finais, divide-se em quatro partes. Na primeira parte, pretendemos analisar as Políticas Educacionais voltadas à Educação Básica. Na segunda parte, discutimos a fundamentação teórico-metodológica das fontes orais. Na terceira parte, estudamos a história das comunidades rurais. $\mathrm{Na}$ quarta parte, investigamos as memórias de gestores de duas importantes escolas rurais.

\section{Políticas Educacionais voltadas à Educação Básica}

O candidato escolhido para assumir a presidência da República, após o golpe civilmilitar de 1964, foi o marechal Humberto de Alencar Castelo Branco, coordenador da conspiração militar. Em 11 de abril de 1964, o Congresso Nacional elegeu Castelo Branco com 361 votos. O ministério mais importante, o da Fazenda, foi entregue a Octavio Gouveia de Bulhões. A outra posição econômica chave, Planejamento e Coordenação Econômica, foi entregue a Roberto de Oliveira Campos. (SKIDMORE, 1988).

Os militares que orquestraram o golpe de 1964 esperavam enfrentar resistência armada. Imaginavam que oficiais legalistas iriam defender João Goulart, mergulhando o país numa guerra civil. Por isso, milhares foram presos pelo Brasil, na chamada Operação Limpeza, inclusive organizações católicas e outras cujas atividades de organização atraíam a suspeita da inteligência militar ou do Departamento de Ordem Política e Social (DOPS), a polícia política. Partidos políticos de esquerda foram atingidos: o Partido Comunista Brasileiro (PCB) e o Partido Comunista do Brasil (PC do B). (SKIDMORE, 1988). 
É interessante discutir a posição da Igreja Católica em relação à Ditadura brasileira. Bispos e padres, na grande maioria, estavam apoiando o golpe de 1964 com a justificativa de que a Igreja temia o avanço do comunismo no Brasil. A participação do clero ocorreu nas duas Marchas da Família com Deus pela Liberdade, a primeira em São Paulo e a segunda no Rio de Janeiro, ambas em 1964. Os eclesiásticos que acompanharam as duas marchas observaram que não havia "[...] um suor de salário mínimo, e iriam descobrir que ali, no asfalto, se caminhava rumo ao regime que tiraria a máscara nos primeiros dias e, através dos anos, se tornaria o maior perseguidor da Igreja Católica no Brasil". (CASTRO, 1984, p. 80).

A Igreja Católica passa a defender a bandeira dos direitos sociais e humanos. Com isso, o catolicismo entra num confronto direto com o Estado, sobretudo após a publicação do AI-5, em 1968. As Comunidades Eclesiais de Base (CEBs) resistem às imposições da Ditadura, abrindo espaços para que os grupos pudessem se expressar religiosa e politicamente. Nesse período, a luta pelos direitos civis, o compromisso com os direitos humanos e a denúncia contra as torturas aumentaram significativamente. Dessa forma, "[...] a contribuição das CEBs se fazia sentir nas denúncias de violência no campo, nas fábricas e no movimento estudantil". (DELGADO; PASSOS, 2009, p. 124).

Desde 1966, após o impacto da repressão, a oposição vinha se articulando. Além da posição de membros da Igreja Católica no Brasil, no início de apoio ao golpe e agora fazendo oposição, os estudantes começaram a se mobilizar ao redor da União Nacional dos Estudantes (UNE). Em 1968, as mobilizações se espalharam pelo Brasil e o que estimulou as manifestações de rua neste ano foi a morte do estudante secundarista Edson Luís, que foi morto pela Polícia Militar em março de 1968, pelo fato de ter protestado contra a qualidade da alimentação dada aos estudantes pobres no Restaurante Calabouço.

Todos esses acontecimentos criaram condições para uma mobilização mais ampla que pôde reunir, além de estudantes, setores representativos da Igreja e da classe média do Rio de Janeiro. O ponto alto dessa convergência foi a passeata dos 100 mil, mesmo após a proibição por meio de uma portaria - de passeatas e manifestações, pelo Ministro da Justiça. As bandeiras dos estudantes lideravam a passeata, porém estavam presentes questões ligadas ao campo das liberdades democráticas, como o fim da censura. Segundo Villa (2014, p. 123) “[...] se no Rio de Janeiro o eixo da manifestação era a defesa das amplas liberdades, portanto, da democracia, em São Paulo, a radicalização da esquerda tinha abandonado a luta no terreno democrático".

$\mathrm{Na}$ área econômica, o país passa pelo chamado milagre econômico, que vai se estender de 1969 até 1973, combinando crescimento econômico com taxas baixas de inflação. "O PIB cresceu na média anual 11,2\% tendo seu pico em 1973 com uma variação de 13\%. A inflação média anual não passou de 18\%". (FAUSTO, 2004, p. 485). Os responsáveis pelo milagre, tendo Delfim Netto à frente, vão se beneficiar de uma situação da economia mundial caracterizada pela disponibilidade de recursos.

O que de fato aconteceu foi uma mudança da política econômica. Se no governo de Castelo Branco devia-se combater a inflação, agora a situação era inversa. Nesse sentido, Prado (2009, p. 223) destaca que a taxa de inflação caiu '[...] de $90 \%$ em 1964, para 38\%, em 1966, e, embora ainda elevada, mantinha-se em queda, o que indicava a existência de alguma margem para priorizar a retomada do crescimento econômico". O mais importante era diminuir a oposição política à Ditadura.

No que se refere à maioria da população brasileira, pode-se dizer que prevaleceu a indiferença em relação à Ditadura Civil-Militar. Boa parte da população era pobre, carente, desinformada e não tinha noção do que estava acontecendo no país. Nas palavras de Couto (1999, p. 99), a verdade é que "[...] essa massa aprovará entusiasticamente o governo Médici, auge da Ditadura. Tudo por causa do impacto favorável da aceleração do crescimento econômico sobre seu cotidiano, principalmente no que diz respeito ao emprego e à renda". Quem sentirá de fato o peso da Ditadura serão políticos, jornalistas, intelectuais, estudantes, entre outros. Essa mentalidade da população só irá mudar após a crise do modelo de crescimento acelerado em 1973. 
No que diz respeito à educação na Ditadura Civil-Militar brasileira, após o golpe de 1964, o Ministério da Educação procurou firmar acordos de cooperação financeira com a agência norte-americana, responsável por auxiliar países subdesenvolvidos em relação à educação. Os acordos envolvendo Ministério da Educação (MEC) e United States Agency for International Development (USAID) incluíram todos os graus de ensino, até o profissional. Tais medidas, orientadas pela doutrina de interdependência, entravam em conflito com a orientação nacional desenvolvimentista, seguida pelas reivindicações dos estudantes.

A partir de 1964, a privatização do ensino, no sentido empresarial, vai ser reforçada. Porém, é importante situar que os mecanismos de reforço à privatização foram os seguintes: "[...] o aumento de repasses dos fundos públicos federais, destinados às escolas privadas, e a criação de uma porcentagem de 5\% do Fundo Nacional do Ensino Superior para as escolas privadas". (COMPARATO, 1987, p. 110). Até então, o Fundo Nacional de Ensino Superior financiava apenas o ensino público. Após o golpe civil-militar, passou a financiar as universidades e escolas privadas também.

Após o golpe de 1964, três atos institucionais e várias emendas modificaram a Constituição de 1946. Assim, no início de 1966, Castelo Branco decide deixar para seu sucessor uma nova Constituição que "[...] incluísse de maneira uniforme e harmônica essas modificações e que representasse a institucionalização dos ideais e princípios da Revolução". Em relação à educação, continua Horta (2001), a Constituição Federal de 1967 propõe três modificações: a gratuidade do ensino oficial para todos deveria ser estendida ao ensino secundário; a gratuidade no ensino superior estaria condicionada não apenas à falta ou insuficiência de recursos dos alunos, mas também ao seu merecimento e seria permitido ao Estado remunerar os professores de religião.

Em relação às verbas para a educação, a Constituição de 1967 não previa nenhuma vinculação orçamentária para a referida área. A emenda Constitucional de 1969 impôs a vinculação orçamentária de $20 \%$ para os municípios apenas. Os índices de investimento destinados à educação estavam abaixo de qualquer investimento que o Estado deveria garantir. Apenas em 1983, com aprovação do Congresso Nacional, da emenda do Senador João Calmon, a chamada Emenda Calmon, teremos a restauração da vinculação de recursos, "[...] 13\% para a União, 25\% para estados e municípios, o que representa um considerável ganho". (CURY; NOGUEIRA, 1986, p. 67). Porém, a área econômica do governo, que era contra a emenda, estava criando formas para não cumprir a nova legislação.

A Lei n. 5.692/71 introduz a distinção entre a terminalidade ideal, que correspondia à escolaridade completa de primeiro e segundo graus com a duração de onze anos, e a terminalidade real, recomendando-se a antecipação da formação profissional de modo a garantir que todos, "[...] mesmo aqueles que não cheguem ao segundo grau ou não completem o primeiro grau, saiam da escola com algum preparo profissional para ingressar no mercado de trabalho". (SAVIANI, 2004, p. 7). Em outros termos, admitiu-se que nas regiões menos desenvolvidas e nas escolas mais carentes, para a população geral, a terminalidade real ficaria abaixo do legal. Nesses casos, o aluno deveria receber algum tipo de preparo profissional para ir ao mercado de trabalho. Em consequência, o Estado brasileiro não foi capaz de democratizar o ensino, ficando distante da organização de uma educação pública democrática a nível nacional.

$\mathrm{Na}$ década de 1970, após a Reforma Universitária, ocorre a implantação das licenciaturas curtas, que expressava a dimensão econômica da educação, encarada como investimento, gerando mercadoria (conhecimento) e mão de obra para o mercado. Nascimento (2012) coloca que os militares justificam a criação das licenciaturas curtas pelo fato da escola média brasileira ter se defrontado com um obstáculo a sua expansão, ou seja, o déficit de pessoal qualificado, que obriga a improvisação de professores em detrimento dos padrões de ensino. A licenciatura curta surge em caráter experimental e emergencial. Na área das Ciências da 
Natureza e da Matemática, como o mais carente em termos de formação de professores, era necessário a criação de um docente polivalente para o ciclo ginasial.

Ressaltamos que essas licenciaturas acentuam a desvalorização do profissional da educação. Acaba colaborando para a perda de autonomia do professor, no processo de ensino e aprendizagem, na medida em que sua preparação para exercer a função docente é mínima. Assim, as licenciaturas curtas cumprem o papel de legitimar o controle técnico e as novas relações de dominação no interior das escolas.

Em 1962, o Conselho Federal de Educação (CFE) cria uma nova disciplina, a Organização Social e Política Brasileira (OSPB). Após o golpe de 1964, o Estado passa a se preocupar com a necessidade de reforçar o ensino de Educação Cívica sob o enfoque da Doutrina de Segurança Nacional, tendo como contrapartida o esvaziamento do ensino da disciplina de História nas escolas de Ensino Fundamental. (FONSECA, 1995).

A partir desse momento, temas como nação, pátria e integração nacional passaram a ser conceitos no centro da disciplina de Educação Moral e Cívica (EMC) criada em 1969, como também deveria marcar o trabalho de todas as áreas específicas com a participação dos docentes e das famílias, convencidos dos mesmos ideais e responsabilidades cívicas. A disciplina de OSPB passa a ser vinculada à Educação Moral e Cívica. Através disso, a ordem e a moral transmitidas visavam eliminar as divergências e tornar hegemônico o poder dos grupos dominantes do Brasil, representado pelos militares. O ensino de Educação Moral e Cívica cumpria o papel de reduzir os conceitos de moral, liberdade e democracia. (CURY; NOGUEIRA, 1986).

A Ditadura brasileira provoca um retrocesso no desenvolvimento da capacidade crítica do país. Isso é medido pela censura ao ensino de primeiro e segundo graus. Smolentzov e Moterani (2013, p. 20) enfatizam que "[...] os livros didáticos eram objeto de suspeição, do mesmo modo que era suspeita, e não sem razão, toda organização escolar consolidada pela Ditadura". Não foi desprezível a luta dos historiadores e geógrafos contra o expurgo da grade curricular de História e Geografia.

Os debates em relação às verbas para a educação e os demais modelos vigentes estiveram em evidência. Devido à exclusão do princípio da vinculação orçamentária, “[...] o governo federal foi reduzindo progressivamente os recursos aplicados na educação: desceu de 7,6\% (em 1970), para 4,3\% (em 1975), recuperando-se um pouco em 1978, com 5,2\%”. (SAVIANI, 2008, p. 296). Paralelamente a essa eliminação da vinculação financeira, a Constituição Federal de 1967 sinalizou na direção do apoio ao ensino privado, quando reza no artigo 168: Respeitadas as disposições legais, o ensino é livre à iniciativa particular, a qual merecerá o amparo técnico e financeiro dos Poderes Públicos, inclusive bolsas de estudo. (BRASIL, 1967).

O resultado de tudo isso foi que, em meados de 1980, o quadro brasileiro era preocupante: “[...] 50\% das crianças repetiam ou eram excluídas ao longo da $1^{\mathrm{a}}$ série do $1^{\circ}$ grau; $30 \%$ da população era analfabeta, $23 \%$ dos professores eram leigos e $30 \%$ das crianças estavam fora da escola". (LIRA, 2010, p. 332). Continua Lira (2010, p. 323) que, além de todo esse quadro alarmante em relação à educação brasileira, "[...] 8 milhões de crianças no $1^{\circ}$ grau tinham mais de 14 anos, $60 \%$ de suas matrículas concentravam-se nas três primeiras séries que reuniam $73 \%$ das reprovações".

No que se refere ao ensino supletivo, Lira (2010, p. 329) destaca que “[...] essa modalidade acabou prejudicando a qualidade do ensino, pois seu caráter intensivo impossibilitou um processo de ensino e aprendizagem mais profundo". No Projeto Minerva, a improvisação de professores e a substituição de monitores e um som distante e estranho indicavam um provável baixo rendimento. Da mesma forma, os diplomas conferidos pelo MOBRAL e pelo Projeto Minerva não melhoraram a situação social de seus portadores, inclusive em vários momentos contribuíram para a deterioração das posições existentes na década de 1980.

A política educacional da Ditadura impossibilitou a democratização da escola pública. Por intermédio da regulamentação educacional da década de 1970, foram colocadas em prática as 
diretrizes que contribuiriam para a crise do ensino público, “[...] o Censo Demográfico de 1970 demonstrou que apenas 357.312 crianças frequentavam a pré-escola, o que correspondia a uma taxa de $4,2 \%$ e as escolas particulares obtinham $40 \%$ das matrículas". (LIRA, 2010, p. 335).

$\mathrm{Na}$ verdade, existia na política educacional brasileira da primeira metade do século XX, a potencialidade do desenvolvimento de um sistema educacional de qualidade para todos, e, desse modo, democrático, mas que foi interrompido pelo golpe civil-militar de 1964 e substituído por um modelo que produziu uma expansão da oferta de um ensino de baixa qualidade. Portanto concluímos que, se houve alguma expansão de uma educação de qualidade para todos, isso ocorreu em um período anterior ao golpe, com as bandeiras liberais, entre elas a universalização do sistema educacional de qualidade.

\section{Fundamentação teórico-metodológica das fontes orais}

O estudo se insere na concepção da História Cultural, campo da história que, no decorrer do século XX, tem expandido suas áreas de estudo e as formas de entender e construir a história. Nesse entendimento, a História Cultural "[...] tem por principal objeto identificar o modo como, em diferentes lugares e momentos, uma determinada realidade cultural é construída, pensada, dada a ler". (CHARTIER, 1990, p, 16).

O grupo social investigado institui o que Borne (1990) denomina de comunidade de memória, baseado no modo como os sujeitos revisitaram o passado e traduziram uma forma para que as práticas culturais fossem narradas. Essas memórias unidas possibilitaram incorporar um tempo social comum, ou seja, um tempo localizado na zona rural.

A história das instituições como lugar construído e que, dessa maneira, é susceptível de ser reconstruída, pela perspectiva de seus significados e representações, "[...] carregam consigo uma determinada interpretação da cultura de um grupo, que pode ser singular, em certa medida; porém, em alguns casos, não pode ser mensurada". (SOUZA, 2015, p. 25). Essa investigação requer o entendimento dos modos distintos de apropriação e do intercâmbio instaurado em um grupo social.

Stephanou e Bastos (2005) salientam que a História Cultural retrata a possibilidade de estudos de novos objetos de pesquisa. Acreditam, por exemplo, no sentido sobre o mundo construído pelos homens do passado e o entendimento dos diferentes processos educativos e escolares. Julia (2001) acrescenta a discussão sobre os estudos de cultura. Ao tratar Cultura Escolar, expressa que seja realizada desde a análise das relações conflituosas ou pacíficas que ela mantém, a cada período de sua história, com o conjunto das culturas que lhe são atuais. Por isso, buscou-se compreendê-la, através de Certeau (2012), uma cultura plural, que integrou as experiências dos diferentes grupos étnicos que souberam requerer escola para os seus, em um determinado espaço de tempo.

Julia (2001) descreve o espaço escolar como um dos elementos fundamentais à constituição de uma cultura escolar. Mesmo que as aulas fossem em casa ou em escolas rurais, nesse processo, percebem-se dois elementos destacados: certa graduação nos conteúdos e um professor, profissional específico para o trabalho, mesmo sem ter formação acadêmica.

A importância social da escolarização é um processo que integrou elementos de diferentes construções identitárias no que diz respeito, aos seus contextos originais, como a relevância da instituição escolar, da presença ao culto ou à missa, as festas e quermesses do lugar. Nas palavras de Souza (2019, p. 226), a tradução cultural da integração, estimulada pela convivência desses diferentes grupos, "[...] instituiu e reatualizou tradições e hábitos que se revestiram em representações que priorizaram a escola como um legado necessário para os filhos dos colonos".

Para entrar na memória do depoente, é necessário que o entrevistador faça um exercício de troca de saberes e reconhecimento de sua atuação social. Este processo está imerso em um universo de contradições, enquanto memória, em face de que, por um lado, "[...] é calcado em um discurso teórico que não se efetiva na prática; e, por outro, em uma prática frutífera 
vinculada em vivências interpessoais do contexto escolar e educativo, em certo contexto sociocultural". (WENCZENOVICZ; SAAB, 2019, p. 107).

No dizer de Grazziotin e Kreutz (2010, p. 16), as memórias, relacionadas à pesquisa, "[...] além da história de uma região, referem-se ao sistema de pensamento, à mentalidade de uma época, a formas de comportamento, valores e prioridades". Elas proporcionam, em determinados momentos, compreender o grau de relevância que algumas questões assumiram na vida de uma comunidade, em detrimento de outras.

Viñao (2000) destaca que a memória não é um espelho fiel do passado, mas um filtro, e o que sai deste filtro nunca será a realidade, é uma reconstituição da realidade, é a interpretação que o indivíduo faz, podendo ser consciente ou inconsciente. Do mesmo modo, Nora (1993) julga a memória como a vida sendo carregada por grupos vivos e, dessa forma, ela está em mudança, aberta ao esquecimento e lembranças, exposta a manipulações, deformações sucessivas e de repentina revitalização. Por consequência, os depoimentos concedem ver os acontecimentos cotidianos como conflitos, mudanças nas práticas pedagógicas, nos locais de trabalho e nas ligações com gestores e empregadores.

A memória não tem o objetivo de instituir o passado como de fato ocorreu, ela traz emoções, conhecimentos e concepções individuais. Portanto demonstra que "[...] a memória por si só não agrega tanto quanto o conjunto, quando tomada juntamente com os documentos pessoais que cada indivíduo guarda ao passar dos anos". (WENCZENOVICZ; SAAB, 2019, p. 108). Assim, ela se torna uma fonte de pesquisa ampla, abrangendo vários grupos sociais.

Segundo Le Goff (2003, p. 409), “[...] a memória é um elemento fundamental para a identidade, individual ou coletiva". A memória, presença real da ausência do passado, do mesmo modo é lembrança, reconhecimento, rememoração. A memória tem o compromisso de não esquecer. Ao trazer o passado para o presente, mediante o processo de narrar, reproduzimos as vivências do passado com referenciais do presente, dando significado ao próprio passado. Nessa perspectiva, a memória é resultado de "[...] um trabalho de seleção e organização do que é importante para o sentimento de unidade e de coerência, o que produz identidade". (ALBERTI, 2006, p. 167). Dessa forma, as memórias que prevalecem em determinado grupo proporcionam compreender esse mesmo grupo ou sociedade.

Pollak (1998) ressalta que, no trabalho com memórias, podem estar os silêncios sobre o passado, os não ditos, que não podem ser entendidos como esquecimentos, visto que a angústia de não encontrar uma escuta, de ser punido por aquilo que se diz, ou ao menos, de se expor ao mal-entendido molda a recordação dos sujeitos. Por isso, a fronteira entre o que é dito e o que não é dito divide "[...] uma memória subterrânea da sociedade civil dominada ou de grupos específicos, de uma memória coletiva organizada que uma sociedade majoritária ou o Estado desejam passar e impor". (POLLAK, 1998, p. 10). Nesse sentido, as memórias ainda são lembradas e solidificadas pelos monumentos, pelo patrimônio arquitetônico, pelas paisagens, pelas datas, pelos personagens históricos, pelas tradições e costumes. Outro aspecto importante é que, como os indivíduos fazem parte de diversos grupos, suas memórias são fracionadas a partir de suas experiências nesses grupos.

A história oral rompe silêncios oriundos do cotidiano, do fazer anônimo, indicando acontecimentos, experiências e concepções que "[...] não se encontram nos documentos escritos e nas versões oficiais da historiografia, o que pode contribuir para uma reconstrução e uma compreensão mais realista do passado". (THOMPSON, 2002, p. 25). No trabalho com a história oral, a narrativa permite que as pessoas memorizem os fatos, que lhes deem sentido, que coloquem suas vivências em uma sequência, que expliquem essas experiências e as relacionem com suas vidas. (MACHADO, 2016).

O grupo social é composto por sete sujeitos, identificados no Quadro 1, que foram gestores nas Escolas Aníbal Magni e Frei Anselmo, que representam o conjunto de memórias, que estão nos documentos elaborados, a partir das narrativas coletadas ao longo da pesquisa. 
Utilizamos nomes fictícios para preservar a identidade e não expor a opinião de nenhum gestor(a). Ressalta-se que a média de idade dos gestores é de 74 (setenta e quatro) anos e a média do período de atuação nas escolas como gestores é de sete anos.

Quadro 1 - Demonstrativo dos sujeitos da pesquisa

\begin{tabular}{|l|l|l|l|}
\hline $\mathbf{N}^{\mathbf{0}}$ & \multicolumn{1}{|c|}{ Nome } & \multicolumn{1}{|c|}{$\begin{array}{c}\text { Data de } \\
\text { nascimento/idade }\end{array}$} & $\begin{array}{c}\text { Período que atuou como gestor(a) nas Escolas } \\
\text { Aníbal Magni ou Frei Anselmo }\end{array}$ \\
\hline 1 & Adalberto & $21 / 08 / 1943-76$ anos & Diretor na Escola Frei Anselmo (1973-1980) \\
\hline 2 & Alice & $25 / 03 / 1944-76$ anos & Diretora na Escola Frei Anselmo (1969-1972) \\
\hline 3 & Luciane & $18 / 10 / 1945-74$ anos & Supervisora na Escola Frei Anselmo (1973-1984) \\
\hline 4 & Pedro & $26 / 09 / 1951-68$ anos & Diretor na Escola Frei Anselmo (1983-1990) \\
\hline 5 & Maura & $03 / 08 / 1954-65$ anos & Supervisora na Escola Frei Anselmo (1976) \\
\hline 6 & Isabel & $12 / 11 / 1941-78$ anos & Diretora na Escola Aníbal Magni (1963-1970) \\
\hline 7 & João & $20 / 02 / 1935-85$ anos & Diretor na Escola Aníbal Magni (1960-1962 e 1971-1980) \\
\hline
\end{tabular}

Fonte: Elaborado pelo autor (2020).

Nessa pesquisa, enfatizou-se o debate do uso das memórias orais como perspectiva investigativa, para o estudo da História da Educação no meio rural, tendo como pressupostos as fontes orais. Além disso, as memórias permitem compreender e entender como as práticas e as culturas escolares foram se estabelecendo no interior das escolas nessas localidades.

Nesse artigo, optou-se pela entrevista narrativa valendo-se da metodologia da História Oral. Usando-se desta modalidade de entrevista, definiu-se um roteiro com questões com foco nas memórias de gestores das Escolas Aníbal Magni e Frei Anselmo durante a Ditadura CivilMilitar brasileira (1964-1985). Pretende-se explorar as seguintes categorias de análise: a) rotina do trabalho do gestor(a); b) relação dos gestores com os professores e a comunidade escolar; c) planejamento nas escolas rurais; d) aprendizagem e frequência dos alunos.

A entrevista é uma técnica relevante que possibilita o desenvolvimento de uma relação entre as pessoas. É uma forma de comunicação que estabelece como a informação é propagada de uma pessoa à outra. O termo mostra a compreensão realizada entre duas pessoas. É o método mais utilizado no trabalho de campo e, por intermédio dela, o pesquisador busca alcançar informes contidos na conversa dos atores sociais. As narrativas ganharam vida tendo em vista que se iniciaram os diálogos entre entrevistador e entrevistado, prosseguindo que o entrevistador deve fortalecer a capacidade de ouvir e de incentivar o fluxo de informações por parte do entrevistado.

As entrevistas possuem aproximadamente 100 (cem) minutos e, após a transcrição, foram textualizadas e apresentadas para os narradores, para que pudessem intervir e aprovar. As entrevistas foram realizadas no mês de dezembro de 2019, a partir de um roteiro elaborado que serviu de referência, visto que o narrador pode "[...] reconstruir sua história pessoal, objetivá-la até certo ponto, como remontar, relatando suas lembranças, do momento presente até a infância ou inverte-lhe o movimento". (PROST, 2008, p. 106).

Destacamos que as entrevistas com os sujeitos da pesquisa foram marcadas com antecedência. Um fato importante foi que todos os entrevistados se colocaram à disposição para contribuir com a pesquisa de Pós-doutorado. Conseguimos realizar as sete entrevistas numa única visita. Todos os sujeitos envolvidos autorizaram o uso de suas entrevistas, desde que fosse utilizado nomes fictícios para preservar a identidade e não expor a opinião de nenhum gestor(a). 


\section{Breve história das comunidades rurais}

Apresentamos, a seguir, a História do Município de Selbach e das comunidades de Arroio Grande, onde se localiza a Escola Municipal de Ensino Fundamental Aníbal Magni e de Linha Floresta, onde se encontra a Escola Estadual de Ensino Fundamental Frei Anselmo. Selbach é um pequeno município com cerca de cinco mil habitantes, localizado no norte do Rio Grande do Sul. Sua colonização inicia em 1905, com a chegada das primeiras famílias de origem germânica. Além disso, para conseguir um lote, o candidato tinha que ser agricultor ${ }^{1}$ e católico ${ }^{2}$. Através da Lei $n$. 4.762/64 foi dada a oportunidade para a criação de novos municípios. Em 22 de setembro de 1965, foi criado o Município de Selbach. Em 13 de maio de 1966, foi instalado o Município e nomeado Benno Ely como interventor federal. (PREFEITURA, 1991).

A trajetória institucional das Escolas Aníbal Magni e Frei Anselmo estão constituídas por um processo de mudanças e alterações de suas designações, no sentido de consultar as comunidades, tendo em vista as diferentes designações das Escolas. Diversos gestores deixaram suas marcas nas instituições de ensino e ainda são lembrados pelas comunidades rurais na atualidade.

A partir de 1910, surgiram os primeiros colonizadores da comunidade de Arroio Grande vindos das Colônias Velhas. Adquiram as terras de Miguel Matte, então procurador do Coronel Jacob Selbach Júnior. Os primeiros colonizadores foram as famílias de Augusto Freiberg, Emílio Bougarth, Guilherme Grafunda e Guilherme Streck, oriundos de Cachoeira do Sul. A fertilidade e o preço baixo dessas terras vinham ao encontro do interesse pessoal desses colonos, porque tinham como objetivo povoar e produzir, bem como um novo lar e uma propriedade, própria para suas famílias. (WEBER; HOLZ, 1999).

As matas densas e a falta de estradas eram algumas das dificuldades que os colonos enfrentaram. A distância era grande, e muitos dias eram consumidos em carroças de bois, cavalos, lombos de burro ou até a pé, para chegar à terra que procuravam. Os colonos dedicavam-se a colonização e a agricultura, buscando sua sobrevivência e seu desenvolvimento econômico. (WEBER; HOLZ, 1999).

Preocupados com o aumento da população na comunidade e com o número elevado de crianças em idade escolar, os colonos acabam incentivando o início da atividade escolar. Entre 1922 e 1931 começa a funcionar a primeira escola na Igreja Luterana. Os alunos não aprendiam o conteúdo na língua portuguesa, apenas na língua alemã. As turmas eram multisseriadas e os professores ensinavam a leitura, a escrita e a matemática (contas).

Em 1956, o número de alunos crescia e era necessário um espaço físico adequado. A Escola muda de lugar e é deslocada para uma casa na propriedade de Lídio Streck. Na década de 1950, por iniciativa de alguns pais de alunos e para melhorar o atendimento às crianças, foi adquirida uma área de terra de Baldoíno Karling. Foi construída uma escola de madeira, inaugurada em 1961. Funcionou até 1974, quando foi destruída por um temporal. (WEBER; HOLZ, 1999).

Em 1975 foi inaugurada a Escola Estadual de $1^{\circ}$ Grau Incompleto Aníbal Magni. Com poucos recursos disponíveis e com o aumento do número de alunos devido ao crescimento da comunidade, o terreno foi cedido ao Estado na administração do prefeito Ilvo Aloísio Barth, na década de 1970. Com o fechamento das escolas rurais das comunidades de São Pascoal, Santa Teresinha e Passo do Padre, devido ao reduzido número de alunos, estes passaram a frequentar a Escola Aníbal Magni. Em 1987, a escola foi municipalizada, recebendo o nome de Escola

\footnotetext{
1 "Ser agricultor: deviam as famílias se comprometer, a iniciar o desmatamento do seu lote e, instalar uma agricultura de subsistência”. (FINGER et al., 1996, p. 2).

2 "Ser católico: como houve núcleos de colonização com conflitos religiosos, o Coronel Selbach optou pela revenda de suas terras em lotes aos católicos. Dessa maneira, assegurava a instalação do núcleo social em suas glebas. Um local determinado e demarcado era destinado para a construção da primeira capela e da primeira escola. A capela e a escola assegurariam a convivência religiosa, cultural e tradicional, conservando a população coesa”. (FINGER et al., 1996, p. 2).
} 
Municipal de $1^{\circ}$ Grau Incompleto Aníbal Magni. Em 1989 foi implantada a $6^{\text {a }}$ série, em 1990 a $7^{\text {a }}$ série e em 1991 a $8^{\mathrm{a}}$ série, passando assim a ser escola de $1^{\circ}$ Grau Completo, denominando-se Escola Municipal de $1^{\circ}$ Grau Aníbal Magni. A partir de 1996, com a promulgação da Lei n. 9.394, passa a chamar Escola Municipal de Ensino Fundamental Aníbal Magni. (WEBER; HOLZ, 1999).

Em 1910, a comunidade de Linha Floresta começa a ser povoada. Os primeiros imigrantes vieram de Venâncio Aires e Roca Sales. Entre as famílias que chegaram em Linha Floresta destacam-se: João Felício de Oliveira, Valentim Nodari, Nicolau Wagner, Mathias Kuhn, Carlos Augusto Bogorny, entre outros. A ocupação de terras aconteceu entre 1910 e 1921. (SEGER, 2002).

A partir de 1925 iniciou-se o ciclo da madeira, que começou a decair na década de 1950, com o extermínio das matas nativas. No final dos anos 1950, surgiu uma opção para o agricultor aumentar a sua renda e consequentes investimentos, através da suinocultura, que se estendeu até o final da década de 1960. A partir deste momento, registra-se na comunidade de Linha Floresta o início da mecanização, com o cultivo de trigo e nos anos 1970 com o cultivo da soja. (SEGER, 2002).

Desde a chegada dos primeiros imigrantes na comunidade de Linha Floresta, houve uma preocupação quanto à educação dos seus filhos. Em 1917, foi construída a primeira escola comunitária na propriedade de Camilo Schneider. Até então, todas as escolas eram construções simples de madeira. A segunda escola que funcionou de forma paralela com a primeira localizase nas terras de Frederico Jacoby. A existência de duas escolas funcionando na mesma época trouxe desavenças entre as pessoas da comunidade e contribuiu para surgir uma terceira escola, numa área doada por José Sestari Filho. (PREDIGER et al., 2017).

No final da década de 1930, foi construída a primeira parte da Escola Frei Anselmo. Esta compunha-se de uma sala somente. A posição do professor em relação ao aluno sempre foi de cima para baixo, o que comprova pelo fato do docente dominar a turma sobre um pedestal, sendo normalmente numa mesa. As classes eram de madeira, com uma tampa, na qual podia-se guardar a sacola de pano e a merenda no seu interior. Sobre a classe havia um pequeno côncavo, onde se colocava o tinteiro quando se escrevia. Geralmente dois alunos ocupavam a mesma classe. (SEGER, 2002).

É relevante destacar a importância da figura do professor na década de 1960, na comunidade de Linha Floresta. O professor era considerado a pessoa mais importante da comunidade. De acordo com Seger (2002, p. 45), “[...] as pessoas em geral respeitavam-no muito e atribuíam-lhe autoridade máxima sobre seus filhos, exigindo, inclusive, que usasse do castigo quando necessário". Em 1977, a Escola muda de nome, depois de um plebiscito, passando a se chamar Escola Estadual de $1^{\circ}$ Grau Frei Anselmo, em homenagem ao primeiro pároco do Município de Selbach. Com a Lei n. 9.394/96, a Escola passa a ser denominada Escola Estadual de Ensino Fundamental Frei Anselmo.

\section{Memórias de gestores de escolas rurais}

A política de Educação Rural necessita muito mais do que um ordenamento legal, pedagógico ou metodológico para que seja efetivada no interior das escolas rurais. Necessita da participação e intervenção dos poderes constituídos, de toda a sociedade, em especial da parcela da sociedade - gestores e docentes, “[...] responsáveis por protagonizar ações de transformação e inclusão, no campo do direito à educação de qualidade, no campo do respeito às diferenças, no campo da educação como prática política de igualdade". (EVANGELISTA, 2016, p. 20).

As práticas educacionais das escolas rurais desejavam um gestor como líder comunitário, religioso e cultural; e, nessa concepção, se constitui e consolida a ação formativa dessas escolas. Ao gestor rural "[...] cabia executar as tarefas de líder comunitário em todas as dimensões da vida". (WERLE, 2012, p. 37). A escola, ao mesmo tempo em que produzia "[...] um líder para o espaço público de comunidades rurais, deixava marcas no indivíduo, consolidando um hábito religioso e de prestação de serviço ao outro”. (WERLE, 2012, p. 37). 
Os gestores, em sua maioria, falam pouco de si mesmos e suas experiências, especialmente dentro do contexto escolar e do lugar social que ocupam. De acordo com Bosi (1994, p. 68), "[...] falar sobre si mesmo e do tempo vivido tem grande importância, pois a narração da própria vida é o testemunho mais eloquente, é como o indivíduo recorda dos acontecimentos, é a sua memória".

Consequentemente, as legislações e a ação dos gestores por meio das Secretarias Municipais de Educação decidiram e impuseram, em outros espaços, a nucleação das escolas rurais, entre as décadas de 1970 e 1980 . Devido ao elevado número de alunos que migraram para as escolas urbanas, sucedeu-se o fechamento de várias escolas do campo. Com a finalização das atividades destes espaços escolares e educativos, perderam-se memórias locais, como escolas e capelas, deixando sociedades inteiramente abandonadas.

O diretor Adalberto (2019) descreve um pouco a sua rotina de gestor em plena Ditadura Civil-Militar na Escola Frei Anselmo:

Tinha todas as funções. Lá era um lugar onde se procurou entrar no Estado como professor. Vinham professores de Passo Fundo e Soledade e queriam o melhor horário. A gente procurou atender a todos da melhor forma. Até quando o professor não podia vir, por exemplo, de Soledade, tinha que substituir o professor sempre pensando no bem do aluno que tinha o objetivo de aprender. (ADALBERTO, 2019).

A supervisora Luciane (2019) destaca que a sua rotina de supervisora escolar era composta de diversas funções:

a gente tinha muita "papelada" para preencher. Tinha muitas reuniões administrativas, tanto na Escola Frei Anselmo como na Delegacia de Educação. Acompanhava o ponto dos professores, cobrava a permanência dos professores em sala de aula, era muito rígido o sistema. Se trazia o CPM para a escola. O diretor tinha um papel fundamental na sociedade. Participava das comissões do município, a gratificação era pequena, era o elo [professor-escola-comunidade]. Participava das atividades religiosas da comunidade. $\mathrm{Na}$ verdade, o diretor era $\mathrm{o}$ "propulsor da educação da comunidade". O diretor era muito consultado, inclusive com problemas familiares [conselhos]. (LUCIANE, 2019).

Em relação à rotina de trabalho do gestor, o diretor Pedro (2019) enfatiza que tudo começava em abrir e fechar todos os dias a Escola.

Não tinha funcionários para fazer esta função. O CPM pagava uma faxineira. A manutenção da Escola era diária, desde o grande pátio, até dentro das salas de aula. A maior preocupação era de como arrumar dinheiro. O Círculo de Pais e Mestres administrava financeiramente a Escola. A participação dos alunos nas mensalidades não fechava o caixa. Tinha que fazer festas e sorteios para arrecadar dinheiro. (PEDRO, 2019).

O diretor João (2019), da Escola Aníbal Magni, salienta que o gestor também era alguém que consertava fechaduras. Nesse sentido,

se tinha algum serviço no prédio [manutenção] era o diretor que fazia. Os alunos eram mais fáceis de trabalhar na época [década de 1970]. 
Faziam as coisas que a gente pedia. A lembrança mais importante que tenho é que onde chego hoje em dia, os ex-alunos reconhecem e pedem como estou. É um reconhecimento do trabalho, significa que algo de importante fiz por eles. (JOÃO, 2019).

Em relação à rotina do gestor(a), é importante salientar que, nas décadas de $1960 \mathrm{e}$ 1970, além de ocupar a função de direção, o gestor(a) era professor(a). Outra preocupação era a falta de recursos. Normalmente se arrecadava recursos para a manutenção das Escolas com festas, onde as comunidades participavam ativamente. Um fato que chama a atenção é o reconhecimento dos discentes em relação ao trabalho dos gestores. Fica clara a importância da figura do diretor(a) nas escolas rurais, pois era o "elo de ligação entre as comunidades e as escolas". Devemos lembrar que era o período da Ditadura Civil-Militar, no qual não existia qualquer liberdade de expressão.

Sobre a relação dos gestores com os professores e a comunidade escolar, a diretora Alice (2019) enfatiza o seguinte:

Fui escolhida para ser diretora da Escola Frei Anselmo por indicação política e por ser alguém da comunidade de Linha Floresta. Até me aposentar na Escola não lembro de ter tido nenhuma eleição para a escolha do diretor. Era a própria Delegacia de Ensino que indicava os professores. A relação foi muito boa com a comunidade, em nenhum momento a gente teve intriga com pais e professores. A gente se encontrava com os pais e os pais procuravam a direção, quando os alunos não aprendiam. A relação era de muito respeito entre a escola e a comunidade. A gente fazia enterros na comunidade, quando o padre não podia vir. (ALICE, 2019).

O diretor Pedro (2019) fala sobre como se tornou gestor da Escola Frei Anselmo e lembra da relação que tinha com os colegas professores e a comunidade escolar. Dessa forma, salienta que

a minha indicação para direção não foi política, não participava de partido político neste período [década de 1980]. O fator mais importante foi por ser do local e conhecer todas as pessoas da comunidade. A relação com os professores e a comunidade escolar era muito boa, especialmente com os pais dos alunos. Entre os professores no decorrer dos oito anos à frente da direção, começou a se manifestar os entraves políticos. Com os alunos a relação era excelente, porque trabalhava com os pais. A escola do interior facilitava muito, o nível de vida e a aceitação. (PEDRO, 2019).

A diretora Isabel (2019) lembra como se tornou diretora na Escola Aníbal Magni e fala da sua relação com os docentes e os pais dos alunos:

Me tornei diretora por causa que tinha Magistério. Não existia eleição para a escolha do diretor. Os pais vinham pouco para a escola. A partir de 1972, já tinha quatro professores na escola. Melhorou muito neste aspecto. Tinha muito respeito e amizade com os professores. Não existia reuniões com os pais. Foi em 1975, que surgiu o CPM. A partir daí se tinha algum problema na Escola se reunia com o CPM quando precisava. No final do ano, tinha a entrega dos boletins e se tinha alguma observação se falava com os pais. (ISABEL, 2019). 
No que diz respeito à escolha do gestor e sua relação com os professores e comunidade escolar, o diretor João (2019) lembra que

não tinha eleição na Escola Aníbal Magni para escolher o diretor. Se dava o processo por indicação e pelo fato de ser o único professor da Escola no início dos anos 1960. A relação com a comunidade escolar tinha que ser boa. Com a minha chegada na comunidade de Arroio Grande, consegui atrair mais alunos na Escola. Tinha uma relação de respeito com os alunos e professores. Tinha o momento dos pais, que era na época da entrega dos boletins, de ouvir o necessário. (JOÃO, 2019).

É relevante observar que, durante a Ditadura (entre 1964 e 1985), não existia eleição para a escolha dos diretores. Era indicação política, normalmente os gestores eram filiados à ARENA ou por ser alguém da própria comunidade e pelo fato de conhecer as pessoas do entorno. Conforme foi relatado, para se chegar à direção, tinha que ter partido político. Os militares conseguiram ficar por duas décadas pelo fato de criar uma teia de apoio nos municípios, além de contar com o apoio da elite política e econômica do país, no caso banqueiros, empresários e grandes produtores rurais. Outro fato marcante era a relação que os gestores possuíam com os docentes e a comunidade escolar. Conforme os relatos, possuíam uma relação de respeito e amizade com os professores. O CPM costumava auxiliar na questão financeira, além de dar apoio total às atividades desenvolvidas nas duas instituições de ensino.

A supervisora Maura (2019) salienta que existia planejamento nas escolas rurais e o mesmo vinha da própria Delegacia de Educação. Nesse sentido,

cada professor tinha que entregar o seu plano. Cobrava muito os professores na questão do planejamento. O planejamento fazia parte do Plano Pedagógico da Escola [Escola Frei Anselmo]. Na frente ia a filosofia da Escola e a função de cada professor. Tinha uma boa relação com os professores e uma estrutura eficiente. (MAURA, 2019).

No que diz respeito ao planejamento, o diretor Pedro (2019) coloca que havia um planejamento sistemático no decorrer dos anos. E acrescenta:

os conteúdos tinham graus ascendentes, de modo que o aluno não deixava nada fora até a $8^{\mathrm{a}}$ série. No meu tempo de diretor, entre 1983 e 1990, se focava a interpretação dentro de todas as disciplinas. A relação era única e exclusivamente com a Secretaria de Educação do Estado. A Delegacia de Educação exigia cópias do que era desenvolvido dentro do planejamento da Escola, mas não tinha nenhum retorno e avaliação. A gente mandava os boletins estatísticos da Escola para a $25^{\mathrm{a}} \mathrm{DE}$. Estes boletins eram as aulas dadas no mês, a questão financeira e a assiduidade dos professores. (PEDRO, 2019).

A supervisora Luciane (2019) ressalta que havia processos de planejamento na Escola Frei Anselmo. Além disso, lembra que

a gente fazia Plano de Curso [valia para o ano todo], Plano Semestral [o que tinha que atingir num semestre], Plano do Bimestre [a cada dois meses] e tinha o Plano Diário que tinha objetivos, conteúdos, metodologia 
e avaliação. Tinha uma boa relação com o município [Selbach], pois independente do partido político, precisava de transporte. Também, tinha uma boa relação com as demais escolas municipais que completavam os estudos na Frei Anselmo. (LUCIANE, 2019).

Sobre o planejamento, a diretora Isabel (2019) relata que o mesmo servia para elaborar os conteúdos do próximo ano da Escola Aníbal Magni. Dessa forma, enfatiza que as reuniões aconteciam em Tapera (município vizinho de Selbach).

Normalmente o pessoal de Soledade vinha até Tapera para planejar. O conteúdo que se trabalhava por série, tinha que enviar até Soledade para ser aprovado. Era conteúdo anual e mensal e disso se fazia o diário. $\mathrm{O}$ pessoal de Soledade era acessível para conversar. Se não tinha a Delegada de Ensino se falava com as assessoras. Para cada setor tinha uma pessoa responsável na $25^{\mathrm{a}}$ Delegacia de Educação de Soledade. (ISABEL, 2019).

Observamos que, a cada início de ano letivo, aconteciam as reuniões entre gestores e docentes nas escolas. O planejamento acontecia diariamente porque fazia parte do Plano Pedagógico das Escolas. O plano diário desenvolvido costumava abordar os objetivos, conteúdos, metodologia e avaliação de cada aula dada. Segundo as memórias, a Delegacia de Educação de Soledade exigia cópias de tudo o que era desenvolvido nas escolas, mas não costumava dar nenhum retorno e avaliação. Isso demonstra que as escolas rurais estavam abandonadas e sem qualquer apoio da parte do governo estadual.

Em relação à aprendizagem e à frequência dos alunos no período da Ditadura CivilMilitar, a diretora Alice (2019) relembra que

os alunos tinham muita dificuldade na aprendizagem, porque falavam tudo em alemão. Eu falava primeiro em alemão para acalmar os alunos e depois falava em português. Houve trocas nas palavras, o $p$ com o $b$, o $t$ com o $d$, o $v$ com o $f$. Os alunos sempre se faziam presente na Escola, mesmo descalços e os pés cheio de barro e pó. Quando explicava a matéria, se percebia quais alunos não tinham tomado o café [sonolentos]. Com o frio do inverno se levava roupas na Escola [Escola Frei Anselmo] para os alunos carentes. No frio e na geada levava uma panela de ferro dentro da sala, com carvão e acendia dentro da sala e as crianças se esquentavam. Também se corria dentro da sala para os alunos se esquentar, devido ao frio, e eles adoravam. (ALICE, 2019).

A supervisora Maura (2019) lembra como se dava a aprendizagem e a frequência dos alunos em meados da década de 1970, na Escola Frei Anselmo, da seguinte maneira:

achava os alunos fracos, fugiam quando chegava perto. Sempre tinha aluno esperto na Matemática. Não fazia parte da cultura dos pais acompanhar os alunos na aprendizagem. Só aprendiam os conteúdos na escola. Os alunos vinham na Escola de transporte escolar, fornecido pela Prefeitura de Selbach e não faltavam. O transporte era muito bem organizado. (MAURA, 2019).

No que diz respeito à aprendizagem e frequência dos alunos, o diretor Pedro (2019) destaca que, na década de 1980, os alunos tinham certa dificuldade 
porque eram oriundos do meio rural, onde se falava muito alemão. A grande dificuldade dos alunos [meninos] era na área da Língua Portuguesa. $\mathrm{O}$ ambiente e a qualidade dos professores facilitavam muito a aprendizagem. Todos estudavam adiante e se formaram em múltiplas áreas, espalhados em todo Brasil. Normalmente todos estavam sempre, faltavam só por motivo de saúde ou por problema na família. Já existia transporte escolar e os alunos vinham mesmo com chuva e frio. Os alunos saíam da escola quando iam morar embora. (PEDRO, 2019).

Por outro lado, a diretora Isabel (2019) fala da aprendizagem e frequência dos alunos no período (1963-1970) de sua gestão na Escola Aníbal Magni. Dessa forma, ressalta que

os alunos tinham bastante dificuldade na aprendizagem. Eram alunos do interior e não tinham acesso a nada. Os pais não tinham conhecimento e não podiam ajudar. Nos dias de chuva faltavam bastante alunos, porque não tinha transporte e as estradas eram precárias. Outra dificuldade da época [década de 1960] era a falta de material. Não tinha caderno, lápis e borracha. Levava sempre lápis de casa para a Escola, para os alunos poderem escrever. A pobreza era grande entre os alunos. A Escola Aníbal Magni pegava alunos de outras comunidades do interior, além do pessoal da vila [Arroio Grande]. (ISABEL, 2019).

Segundo as memórias dos gestores, de modo geral, os alunos oriundos do interior apresentavam muitas dificuldades em relação à aprendizagem. Pelo fato de falar a língua alemã em casa, apresentavam sérios problemas na disciplina de Língua Portuguesa, porque costumavam trocar as palavras. Muitos alunos vinham com fome na escola, de acordo com os relatos, e esta questão acabava interferindo na aprendizagem. Além disso, não existia acompanhamento da parte dos pais, pelo fato de serem agricultores com baixa escolaridade. A partir de meados dos anos 1970, o Município de Selbach passa a ter transporte escolar público e gratuito. Isso favorece a presença dos alunos nas escolas e passa aumentar a frequência dos mesmos, inclusive nos dias chuvosos e de geada em pleno inverno rigoroso.

Percebemos que o autoritarismo vigente entre os anos de 1960 e 1980 não atingiu as Escolas Aníbal Magni e Frei Anselmo. Acreditamos que foi pelo fato de as escolas estarem localizadas em zonas rurais, e também pelo motivo dos gestores terem afinidades ideológicas com as políticas educacionais da Ditadura. Além disso, a população rural desconhecia os excessos cometidos pelos governos militares, tais como torturas, perseguições e, inclusive, assassinatos de presos políticos, pois não tinham acesso à informação.

\section{Considerações finais}

As leis impostas pela Ditadura Civil-Militar brasileira no ensino e na formação profissional inauguraram uma série de ações do Estado, com o objetivo de executar um papel na reprodução ampliada do capital, que se prolongou além do processo de qualificação desta força, visto que essas políticas setoriais atingiram a pesquisa científica, as inovações tecnológicas, a assistência social e o consumo coletivo. Nesse cenário, a legislação foi decisiva na reprodução estendida da força de trabalho.

A política social dos governos militares, adotada desde 1964, representou-se na preponderância dos aparatos repressivos, colocados na posição de frente na guerra contra as classes populares, com o objetivo de separar suas organizações e suas lutas por alterações estruturais na sociedade brasileira. Em resumo, no campo da educação, as heranças da 
legislação de ensino da Ditadura resultaram na privatização do ensino e na proletarização de boa parte da categoria de docentes do país.

O conceito de memória orienta os pressupostos teóricos da investigação, visto que se trabalha com a concepção metodológica da História Oral. A memória apresenta suas limitações por ser uma reconstrução atualizada do passado. Ciente disso, realizamos entrevistas com gestores que atuaram em escolas rurais, na Escola Aníbal Magni e na Escola Frei Anselmo, no período que compreende a Ditadura Civil-Militar, entre 1964 e 1985, ou seja, a mais de três décadas. Um fato positivo foi a disponibilidade dos gestores em contribuir na pesquisa de Pós-doutorado. Talvez pela razão de ser morador do pequeno Município de Selbach, isso tenha ajudado.

O componente político era o modo como chegavam à função de gestor(a), alguns por indicação política, outros por pertencerem ao quadro de funcionários; assim, conquistava-se facilmente o cargo pretendido. A conquista é relacionada a outro componente que é a territorialidade, entendida como a ação dos gestores no espaço escolar e a seu redor, sua permanência no cargo. O componente normativo, que foram dispositivos legais que padronizam as ações dos gestores no cotidiano escolar, procuram mencionar que buscavam atuar de acordo com as normas encaminhas pela Delegacia de Educação. Por fim, a experiência docente, que se apoia no tempo em que foram professores, uma vez que o saber técnico e pedagógico foi essencial para estabelecer suas práticas administrativas.

No que diz respeito ao perfil dos gestores escolares, prevalece o foco no pedagógico, dado que os gestores eram responsáveis por conduzir questões de ensino e aprendizagem, ao lado dos docentes. Além do perfil multifuncional, quer dizer, que exerce muitas funções na escola, entre elas, pedagógica, financeira e de recursos humanos. Assim sendo, que quando foram questionados sobre a função dos gestores entre os anos 1960 e 1980, a concepção multifuncional foi uma temática. Consideremos que os gestores colaboraram com a educação das comunidades onde atuaram, isto fica evidente nas narrativas de memória, no reconhecimento que recebem dos seus ex-alunos.

Para finalizar, as memórias dos gestores das Escolas Aníbal Magni e Frei Anselmo proporcionam momentos de claridade e novas concepções. As memórias possibilitam uma visibilidade ao cotidiano escolar, seus espaços e tempos, como por exemplo, a relação de respeito que existia entre gestores, docentes e as comunidades rurais, assim como as dificuldades na própria aprendizagem, principalmente nas disciplinas de Língua Portuguesa e Matemática, além do temor de criticar os crimes cometidos ao longo da Ditadura Civil-Militar dentro do espaço escolar.

\section{Referências}

ALBERTI, Verena. Histórias dentro da história. In: PINSKY, Carla Bassanezi (Org.). Fontes históricas. São Paulo: Contexto, 2006. p. 155-202.

BORNE, Dominique. Comunidade de memória e rigor crítico. In: BOUTIER, Jean; JULIA, Dominique. Passados recompostos: campos e canteiros da história. Rio de Janeiro: UFRJ/FGV, 1998, p. 133-141.

BOSI, Ecléa. Memória e sociedade: lembranças de velhos. São Paulo: Companhia das Letras, 1994

BRASIL. Constituição Federal do Brasil (1967). Brasília: Senado, 1967.

CASTRO, Marcos de. 64: conflito igreja x estado. Rio de Janeiro: Vozes, 1984.

CERTEAU, Michel de. A cultura no plural. Tradução: Enid Abreu Dobránsky. 7.ed. Campinas, SP: Papirus, 2012. 
CHARTIER, Roger. A História Cultural entre práticas e representações. Portugal: DIFEL Difusão Editorial S.A., 1990.

COMPARATO, Fábio Konder. Educação, Estado e Poder. São Paulo: Brasiliense, 1987.

COUTO, Ronaldo Costa. História indiscreta da ditadura e da abertura: Brasil 1964-1985. 3.ed. Rio de Janeiro: Record, 1999.

CURY, Carlos Roberto Jamil; NOGUEIRA, Maria Alice. O atual discurso dos protagonistas das redes de ensino. In: CUNHA, Luiz Antônio (Org.). Escola pública, escola particular e a democratização do ensino. São Paulo: Autores Associados, 1986, p. 65-93.

DELGADO, Lucilia de Almeida Neves; PASSOS, Mauro. Catolicismo: direitos sociais e direitos humanos (1960-1970). In: FERREIRA, Jorge; DELGADO, Lucilia de Almeida Neves (Orgs.). O tempo da ditadura: regime militar e movimentos sociais em fins do século XX. 3.ed. Rio de Janeiro: Civilização Brasileira, 2009. p. 93-129.

EVANGELISTA, Abigail Bastos. A gestão de escolas rurais no contexto das políticas públicas de educação do campo. 2016. 172f. Tese (Doutorado em Educação Escolar) - Programa de PósGraduação em Educação Escolar, Universidade Estadual Paulista “Júlio de Mesquita Filho”, 2016.

FAUSTO, Boris. História do Brasil. 12.ed. São Paulo: Editora da Universidade de São Paulo, 2004.

FINGER, Marcos et al. Trabalho de Sociologia: a História do Município de Selbach. Escola Agrotécnica Federal de Sertão, 1996.

FONSECA, Selva Guimarães. Caminhos da história ensinada. 3.ed. Campinas, SP: Papirus, 1995.

GRAZZIOTIN, Luciane Sgarbi Santos; KREUTZ, Lucio. Processo de escolarização e formação docente dos professores nas antigas colônias de imigração italiana no nordeste do Rio Grande do Sul (1920-1940). In: VIII CONGRESSO Luso-Brasileiro de História da Educação, 2010, São Luís (MA). Anais Eletrônicos, Infância, juventude e relações de gênero. São Luís (MA), p. 1-18, 2010.

HORTA, José Silvério Baía. A Educação no Congresso Constituinte de 1966-67. In: FÁ VERO, Osmar (Org.). A Educação nas constituintes brasileiras 1823-1988. 2.ed. Campinas, SP: Autores Associados, 2001. p. 201-239.

JULIA, Dominique. A cultura escolar como objeto histórico. Tradução: Gizele de Souza. Revista Brasileira de História da Educação, Campinas, SP, n. 1, p. 9-44, jan./jun. 2001.

LE GOFF, Jacques. História e memória. Campinas: Editora Unicamp, 2003.

LIRA, Alexandre Tavares do Nascimento. A legislação da educação no Brasil durante a ditadura militar (1964-1985): um espaço de disputas. 2010. 367f. Tese (Doutorado em História Social) Programa de Pós-Graduação em História Social, Universidade Federal Fluminense, 2010.

MACHADO, Cláudia Aparecida Ferreira. A infância na escola rural de Montes Claros (MG) da década de 1960 à de 1980: memórias e representações de professores. História Oral, v. 19, n.2, p.133-153, jul./dez. 2016. 
NASCIMENTO, Thiago Rodrigues. A criação das licenciaturas curtas no Brasil. Revista HISTEDBR On-line, Campinas, n.45, p.340-346, mar.2012. https://doi.org/10.20396/rho.v12i45.8640153

NORA, Pierre. Entre memória e história: a problemática dos lugares. Tradução: Yara Aun Khoury. Projeto História, n. 10, p. 7-28, dez. 1993.

POLLAK, Michael. Memória, esquecimento, silêncio. Tradução: Dora Rocha Flaksman. Estudos Históricos, Rio de Janeiro, v. 2, n. 3, p. 3-15, 1989.

PRADO, Luiz Carlos Delorme; EARP, Fábio Sá. O milagre brasileiro: crescimento acelerado, integração internacional e concentração de renda (1967-1973). In: FERREIRA, Jorge; DELGADO, Lucilia de Almeida Neves (Orgs.). O tempo da ditadura: regime militar e movimentos sociais em fins do século XX. 3.ed. Rio de Janeiro: Civilização Brasileira, 2009. p.207-235.

PREDIGER, Cirlei Ivoni Schuvaab et al. (Orgs.). Linha Floresta: um século de educação, amor e união. Tapera: LEW Editora, 2017.

PREFEITURA Municipal de Selbach. Diagnose: estudo e análise. Secretaria Municipal de Saúde e Meio Ambiente, 1991.

PROST, Antoine. Doze lições sobre a História. Belo Horizonte: Autêntica, 2008.

SAVIANI, Dermeval. A nova lei da educação: trajetória, limites e perspectivas. 9.ed. Campinas, SP: Autores Associados, 2004.

SAVIANI, Dermeval. O legado educacional do regime militar. Cad. CEDES, v. 28, n. 76, Campinas, p. 291-304, set./dez. 2008. https://doi.org/10.1590/S0101-32622008000300002

SCHNEIDER, Inque; WENTZ, Neusa Maria Erbes. Um povo e suas histórias. Prefeitura Municipal de Selbach. Secretaria Municipal de Educação, 1992.

SEGER, Rudi. Brava gente: a história da comunidade de Linha Floresta. Tapera: Gráfica Taperense Ltda, 2002.

SKIDMORE, Thomas. Brasil: de Castelo a Tancredo, 1964-1985. Tradução: Mario Salviano Silva. Rio de Janeiro: Paz e Terra, 1988.

SMOLENTZOV, Vera Maria Neves; MOTERANI, Geisa Maria Batista. Ditadura militar e a repercussão sobre o currículo oficial no Brasil. Avesso do Avesso, v. 11, n. 11, p. 17-24, nov. 2013.

SOUZA, José Edimar de. As escolas isoladas: práticas e culturas isoladas no meio rural de Lomba Grande/RS (1940-1952). 2015. 292f. Tese (Doutorado em Educação) - Programa de Pós-Graduação em Educação, Universidade do Vale do Rio dos Sinos, 2015.

SOUZA, José Edimar de. A escola isolada: contribuições e processos de escolarização em Novo Hamburgo, RS (1940-1952). Série-Estudos, Campo Grande, MS, v. 24, n. 50, p. 219-238, jan./abr. 2019. https://doi.org/10.20435/serie-estudos.v24i50.1131 
STEPHANOU, Maria; BASTOS, Maria Helena Câmara. História, memória e história da educação. In: STEPHANOU, Maria; BASTOS, Maria Helena Câmara (Orgs.). História e memórias da educação no Brasil. Petrópolis, RJ: Vozes, 2005, v. 3, p. 416-430.

THOMPSON, Paul. História oral e contemporaneidade. Tradução: Andréa Zhouri e Lígia Maria Leite Pereira. História Oral, v. 5, p. 9-28, 2002.

VIÑAO, Antonio. Las autobiografias, memórias y diários como fuente histórico-educativa: tipologia y usos. Revista Teias, Rio de Janeiro, n. 1, p. 82-97, 2000.

VILLA, Marco Antonio. Ditadura à brasileira: 1964-1985: a Democracia Golpeada à Esquerda e à Direita. São Paulo: LeYa, 2014.

WEBER, Maria Cristina Backes; HOLZ, Nilsa Maria. A história de Arroio Grande. Tapera: Gráfica Taperense Ltda, 1999.

WENCZENOVICZ, Thaís Janaina; SAAB, Ana Laura Ferreira. Identidade e memória docente: uma perspectiva de ressignificação histórico-social no Alto Uruguai (Corede Norte). Revista Conexão $U E P G$, v.15, n.1, p.106-113, jan./abr. 2019. https://doi.org/10.5212/Rev.Conexao.v.15.i1.0014

WERLE, Flávia Obino Corrêa. Escola normal rural: espaço de formação de grupos dirigentes. Olhar de professor, Ponta Grossa, v.15, n.1, p.33-39, 2012. https://doi.org/10.5212/OlharProfr.v.15i1.0002

\section{Fontes orais}

ADALBERTO [76 anos]. [dez. 2019]. Entrevistador: Darciel Pasinato. Selbach, RS, 09 dez. 2019.

ALICE [76 anos]. [dez. 2019]. Entrevistador: Darciel Pasinato. Selbach, RS, 10 dez. 2019.

ISABEL [78 anos]. [dez. 2019]. Entrevistador: Darciel Pasinato. Selbach, RS, 11 dez. 2019.

JOÃO [85 anos]. [dez. 2019]. Entrevistador: Darciel Pasinato. Selbach, RS, 12 dez. 2019.

LUCIANE [74 anos]. [dez. 2019]. Entrevistador: Darciel Pasinato. Selbach, RS, 12 dez. 2019.

MAURA [65 anos]. [dez. 2019]. Entrevistador: Darciel Pasinato. Selbach, RS, 10 dez. 2019.

PEDRO [68 anos]. [dez. 2019]. Entrevistador: Darciel Pasinato. Selbach, RS, 09 dez. 2019. 